\title{
К ВОПРОСУ О СТИЛИСТИЧЕСКОМ ПРИЕМЕ ДВОЙНОЙ АКТУАЛИЗАЦИИ ЗНАЧЕНИЯ ФРАЗЕОЛОГИЧЕСКИХ ЕДИНИЦ С КОМПОНЕНТОМ-30ОНИМОМ В АНГЛИЙСКИХ И АМЕРИКАНСКИХ ХУДОЖЕСТВЕННЫХ ТЕКСТАХ ХХ ВЕКА
}

\begin{abstract}
ON THE ISSUE OF STYLISTIC DEVICE OF DOUBLE ACTUALIZATION OF THE PHRASEOLOGICAL UNITS MEANING WITH A ZOONYM COMPONENT IN THE ENGLISH AND AMERICAN FICTION TEXTS OF THE XXTH CENTURY
\end{abstract}

\section{O. Novikova}

Summary: The article is devoted to the analysis of double actualization as an effective device of structural and semantic transformations of animal phraseological units in the English-language fiction of the XXth century. The relevance of the work is determined by the need to study contextual modifications of phraseological units with a zoonym component which lead to creating some new semantic shades and new artistic quality. The examples of productive stylistic occasional transformation techniques of the language units in question demonstrate the ability to perform their pragmatic function. The author underlines the fact that animal idioms act in literary texts as intensifiers of purposeful influence on the addressee. The role of double actualization in creating a humorous effect is considered.

Keywords: double actualization, phraseological units, componentzoonym, English language literature of the XXth century, structuralsemantic transformations, pragmatic effect, expressiveness.
$\mathrm{O}$ дним из постулатов современной лингвистики является признание коммуникативной функции ведущей функцией языка, согласно которой язык служит не только для обмена мыслями, но и для выполнения определенных коммуникативно-прагматических установок. Коммуникативный подход к языковым явлениям позволяет увидеть, что фразеологические единицы способны выполнять одновременно как информативную, так и прагматическую функцию, центральным проявлением которой является функция речевого воздействия.

Теоретические основания лингопрагматики были заложены к 60-м гг. XX века трудами лингвистов-философов Оксфордской школы (Б. Рассел, Дж. Остин, Х. Грайс, Дж. Серл).
Новикова Ольга Вячеславовна

К.фрилол.н., доцент, Московский авиационный институт (Национальный исследовательский университет) Novikova_English@mail.ru

Аннотация: Статья посвящена анализу двойной актуализации как эффективного приема структурно-семантического преобразования фразеологических единиц, номинирующих животных, в англоязычной художественной литературе XX века. Актуальность работы определяется необходимостью изучения контекстуальных трансформаций фразеологических единиц с компонентом-зоонимом, в результате которых создаются новые смысловые оттенки, появляется их новое художественное качество. Приведенные примеры продуктивного стилистического приема окказиональной модификации исследуемых языковых комплексов демонстрируют их способность в осуществлении прагматической функции языка. Автор подчеркивает, что фразеологизмы с зоонимами выступают в художественных текстах в качестве интенсификаторов целенаправленного воздействия на адресата. Рассматривается роль двойной актуализации в создании юмористического эффекта.

Ключевые слова: двойная актуализация, фразеологические единицы, компонент-зооним, англоязычная литература XX века, структурно-семантические преобразования, прагматический эффект, экспрессивность.
Прагматика прочно вошла в сферу пристального внимания современной лингвистики. В работах отечественных исследователей $[1 ; 2 ; 3 ; 4 ; 5]$ освещается широкий спектр вопросов, касающихся прагматического аспекта функционирования языковых единиц в тексте и прагматики дискурса. В фокусе внимания зарубежных языковедов $[6 ; 7 ; 8 ; 9 ; 10 ; 11 ; 12 ; 13 ; 14 ; 15 ; 16 ; 17 ; 18 ; 19 ; 20]$.оказываются вопросы прагматического потенциала текста в коммуникативном контексте и проблема воздействия на адресата.

В современных лингвистических исследованиях фразеологические единицы (ФЕ) рассматриваются как специфические единицы, обслуживающие прагматику языка, которые способны кратко и точно оценивать ситуацию и доводить самую ее суть до сознания читающего или слушающего, апеллируя к его чувству юмора и основным эмоциям. 
Особое место в английском языке занимают фразеологические единицы с компонентом-зоонимом (ЗФЕ), под которыми подразумевают устойчивые сочетания слов с названиями животных, не образующиеся по порождающим структурно-семантическим моделям переменных сочетаний.

ЗФЕ достаточно широко используются благодаря тому, что являются древнейшей, наиболее репрезентативной частью фразеологического фонда английского языка и используются для характеристики внешности и поведения человека, для описания различных жизненных ситуаций.

Поскольку условием прагматического успеха является апелляция к эмоциональному восприятию сообщения, художники слова активно используют эмотивно окрашенные ЗФЕ в своих произведениях.

Выбор подобного объекта исследования продиктован тем непреложным фактом, что они являются экспрессивными и способны производить на реципиента определенный и весьма высокий прагматический эффект.

Прагматический эффект, т.е. адекватность или неадекватность коммуникации намерению адресанта зависит, прежде всего, от той формы, в которую облекается содержание [3, с. 11].

Анализируемые единицы включаются в ткань художественной речи как в своей узуальной, так и в окказиональной форме.

При узуальном использовании ЗФЕ реализуются в своем словарном значении и форме. Под окказиональным стилистическим использованием ЗФЕ мы, вслед за А.С. Начисчионе, понимаем «уникальную стилистически окрашенную актуализацию ее в речи, в результате которой происходят значительные изменения формы и значения ФЕ, определяемые контекстом» $[28$, c. 240$]$.

Отграничение окказионально преобразованных ЗФЕ от узуального употребления ЗФЕ проводилось посредством приема оппозиций.

Обозначенный лингвистический феномен давно занимает умы лингвистов. За последние годы опубликовано много работ, в которых освещаются вопросы использования окказиональных трансформаций ФЕ на примере разных языков [21; 22; 23; 24; 25; 26; 27; 28].

Однако малоизученным остается вопрос окказиональных модификаций ЗФЕ. Незначительное количество исследований посвящено этой теме [29; 30; 31].
В данной статье рассматриваются особенности стилистического приема двойной актуализации ЗФЕ в художественных текстах англоязычных авторов XX века.

Окказиональные преобразования ЗФЕ основаны на окказиональных изменениях в составе, количестве и порядке следования компонентов. При сохранении традиционного количества компонентов трансформация носит квалитативный характер, при отклонении от этого количества - квантитативный [31, с. 437].

Используя компонентный, контекстуальный и описательный методы, было выявлено, что англоязычные прозаики часто прибегают к структурно-семантическим преобразованиям 3ФЕ, в которых наиболее ярко проявляется их языковая специфика - раздельнооформленность и семантическая цельность. В результате окказиональных модификаций ЗФЕ прослеживается изменение ее формальной структуры, которое достигается в результате реализации следующих стилистических приемов: вклинивание переменных компонентов в состав ЗФЕ, добавление переменных компонентов к началу или концу ЗФЕ, сокращение количественного состава ЗФЕ (эллипсис), замена компонентов ЗФЕ, двойная актуализация значения ЗФЕ, повтор ЗФЕ.

Выбор темы исследования обусловлен отсутствием специальных исследований двойной актуализации значения английских фразеологизмов с зоонимами.

Актуальность рассмотрения прагматического потенциала ЗФЕ на примере использования описываемого стилистического приема определяется все возрастающим интересом современной лингвистики к функциональным особенностям языковых единиц и их системным контекстным модификациям. Речевые инновации ЗФЕ представляют собой осознанные и преднамеренные действия субъекта речи для сообщения дополнительной экспрессии как самой 3ФЕ, так и контексту, в котором реализуется ее значение и прагматическая заданность.

Действенный прием двойной актуализации значения ЗФЕ ориентирован на достижение эффекта двуплановости (посредством одновременной реализации), который заключается в обыгрывании значения ЗФЕ и буквального значения словосочетания, являющегося ее прототипом или отдельных компонентов этого словосочетания. В данный процесс может быть вовлечено либо значение всего словосочетания в целом, либо буквальная интерпретация одного или нескольких компонентов ЗФЕ. В результате возникает неожиданное столкновение двух планов восприятия.

Для исследования двойной актуализации ЗФЕ были использованы 124 единицы, извлечённые методом 
сплошной выборки из английских и американских художественных текстов XX века, обращение к которым мотивировано тем, что эти произведения отличаются исключительной лингвокреативностью, демонстрируя при этом определенный этап развития языка и культуры англоязычного народа.

Новизна работы заключается в выявлении прагматической обусловленности двойной актуализации значения устойчивых словесных комплексов, что имеет большое значение для лингвопрагматики.

Практическая ценность исследования определяется возможностью прикладного использования ее теоретических положений и иллюстративного материала в лекционных курсах по фразеологии, экспрессивной стилистике современного английского языка, интерпретации текста и прагмалингвистике.

Обозначенный прием находится в фокусе внимания таких исследователей, как Ю.А. Киссел [32]; А.В. Кунин [33], А.С. Начисчионе [34]; Э.И. Халатникова [35]. Впервые в английской фразеологии данный прием был рассмотрен А.В. Куниным. В немецкой фразеологии рассматриваемый вид преобразования был изучен Л.М. Болдыревой [36], которая ввела в лингвистический обиход термин «двойная актуализация» (ДА).

Рассматривая прием ДА, целесообразно отделять технические приемы от стилистического эффекта. В английской фразеологии такие приемы, как добавление, замена компонентов, эллипсис и другие как бы «подготавливают почву» для стилистического эффекта, производимого приемом ДА [35, с. 73].

Отправной точкой использования приема ДА является цель высказывания, которая заключается в том, чтобы охарактеризовать персонажа произведения.

Рассмотрим случаи использования приема ДА на примере ЗФЕ wouldn't hurt a fly «мухи не обидит»:

'Whose daughter did you expect her to be?'

'You don't apprehend my meaning, Lord I.,' said Mr Pott patiently.

'I meant that she takes after her dear mother in having a sweet nature. Her dear mother had the loving kindness of an angel or something, and so has Polly. That's what I meant. Her dear mother wouldn't hurt a fly, nor would Polly hurt a fly. I've seen her dear mother take a fly in her hand -' [37, c. $155]$.

Данное высказывание проникнуто чувством глубокой симпатии говорящего к адресату и нацелено на передачу положительного, почтительного отношения к персонажу.

В этом фрагменте текста воскрешению угасшей образности ЗФЕ wouldn't hurt a fly служит прием ДА. Посредством столкновения прямого и переносного значений обозначенной ЗФЕ в сознании читателя возникает образ героя произведения, который весьма робок и мухи не обидит. Апелляция к чувственному началу достигается путем буквальной «расшифровки» компонента fly.

Анализ иллюстративного материала показывает, что прием ДА используется только в диалогической речи, при этом обновление ЗФЕ может встречаться либо в пределах высказывания говорящего, о чем свидетельствует вышеприведенный пример, либо распределяться между репликами двух коммуникантов.

Из 124 случаев рассмотренного контекстуального употребления ЗФЕ в 120 примерах в процессе коммуникации используется реплика-подхват, которая выражает эмоционально окрашенную реакцию говорящего на реплику собеседника. В таком случае реплика-подхват является новым сообщением, которое развивает диалог:

I stepped back, slipping the torn package into the inside breast pocket of my jacket. "Turn around slowly, hands on the head. And tell me who'd pay you ten thousand dollars for bumping off an old lady with a weak heart."

He turned, his blank face twisting, trying to get the feel of a story to tell. His fingers scratched unconsciously in his hair. "You got me wrong, I wouldn't hurt a fly."

"If it was big enough to bite back, you wouldn't" [38, c. 124].

Герой произведения обращается к ЗФЕ wouldn't hurt a fly в оправдательном ключе, с целью снять с себя обвинение в смерти пожилой женщины. Собеседник же буквализирует упомянутую ЗФЕ, иронично замечая, что «он не обидит большую муху, которая сможет сама укусить», т.е. не сможет обидеть человека, который способен сам за себя постоять. Таким образом, посредством ДА значения исходной ЗФЕ дается отрицательная характеристика персонажа произведения.

Приведенные приемы свидетельствуют о том, что в результате использования приема ДА на адресата воздействует сложный эмоциональный заряд, переносное значение ЗФЕ, буквальное значение прототипа ЗФЕ и наглядный зрительный образ, т.е. имеет место многоканальная передача информации, что и способствует созданию прагматического эффекта.

Стилистический прием ДА является источником юмористического эффекта. Шутливо-ироническое обы- 
грывание ЗФЕ возникает в результате ДА в том случае, когда отправитель речи использует ЗФЕ, а реципиент воспринимает данную единицу как переменное словосочетание и наоборот. Восстановление прямого значения всей ЗФЕ может осуществляться последующим обыгрыванием ее буквального значения в реплике второго говорящего:

Lord Emsworth hastened to point out that the present was a special case.

'You can't be bitten by the Empress.'

'Oh, no? Who made that rule?'

'She's as gentle as a lamb.'

\section{'I was once bitten by a lamb.'}

Lord Ickenham was surprised [37, c. 61].

В приведенном контексте ЗФЕ as gentle as a lamb «кроток как ягненок» воспроизводится в своей узуальной форме, а развитие образа, лежащего в ее основе, достигается употреблением в следующем, непосредственно за данной 3ФЕ, предложении. Создается комический эффект, поскольку идет параллельное восприятие буквального смысла сочетания и переносного в ЗФЕ.

Впервые в английской фразеологии Э.И. Халатникова выделяет понятие цепочки двойной актуализации, под которой понимается несколько окказиональных преобразований ФЕ, которые реализуются в репликах разных персонажей и создают единый стилистический эффект ДА. Звеном цепочки является реплика первого персонажа [39, с. 217].

Наблюдения над исследуемым языковым материалом показывают, что наиболее частотную группу составляют цепочки минимальной сложности, которые состоят из одного окказионального приема, который обязательно сопровождается обыгрыванием значения ФЕ, что ведет к буквализации ФЕ [39, с. 219].

Обратимся к одному из примеров приема ДА, демонстрирующих цепочку минимальной сложности:

'Oh, do stop splitting hairs. They're all French, aren't they? And when it comes to dealing with each other, there's no flies on them.

When the heavier luggage had been unloaded on to the quay, the passengers clustered round with their porters to identify their own. 'Like flies round a cow pat', said Atalanta, who often used country similes although she lived in London in the holidays and a cathedral city in the term. She seemed to have flies rather on her mind at the moment $[40$, c. 37].

ЗФЕ there's no flies on someone «их не проведешь, он начеку, они надежны, безупречены» обыгрывается в по- следующей реплике посредством использования сравнительного оборота like flies round a cow pat, интенсифицируя признак большого количества, сравнивая людей с мухами, скопившимися на навозной куче.

Ироничное отношение автора к своей героине подчеркивается повторным обыгрыванием компонента flies благодаря использованию дополнительных переменных компонентов rather on her mind. Таким образом, компонент flies имеет различную референтную соотнесенность, которая актуализируется за счет двух приемов - двойной актуализации и добавления компонентов в одном микроконтексте.

В свете вышеизложенного подчеркнем, что поскольку потенциальные прагматические возможности ЗФЕ раскрываются в контексте, для изучения двойной актуализации значения ЗФЕ в качестве предмета исследования был рассмотрен прагматический потенциал контекстуально преобразованных 3ФЕ, которые обладают высоким зарядом экспрессии.

Особый интерес представляют окказиональные модификации ЗФЕ в произведениях англоязычных прозаиков XX века. Проведенный анализ 124 примеров контекстуального употребления ЗФЕ свидетельствует о том, что фразеологическое творчество писателей прошлого века проявляется в поиске новых неожиданных форм выражения и обновлении хорошо известных читателю узуальных форм ЗФЕ.

Окказиональное расширение выразительных потенций исследуемых единиц за счет двойной актуализации значения ЗФЕ возвращает им исконную красочность, позволяет поменять оценку с положительной на отрицательную, усилив ее экспрессивность в контексте.

Двойная актуализация значения ЗФЕ является наиболее распространенным лингвистическим феноменом, который служит для оживления потускневшего образа, конкретизации значения ЗФЕ и его эмоционально-стилистического воздействия на реципиента.

Описываемый стилистический прием предполагает наложение фразеологически связанного значения на свободное сочетание, что способствует созданию юмористического эффекта в диалогической речи.

В ходе исследования были выявлены цепочки минимальной сложности, которые составляют наиболее частотную группу ДА. Они состоят из одного окказионального приема, который обязательно сопровождается обыгрыванием значения ЗФЕ

Различные перевоплощения 3ФЕ дают представление об их речевых возможностях, поэтому изучение двойной 
актуализации ЗФЕ вносит вклад в выявление закономерностей развития фразеологической системы английского языка и представляет определенный научный интерес.

Актуальность предпринятого исследования определяется необходимостью дальнейшего изучения автор- ских преобразований ЗФЕ, поскольку язык художественной литературы отличается образностью и широким использованием таких изобразительно-выразительных средств английского языка, как ЗФЕ, которые составляют многочисленную группу фразеологического фонда английского языка.

\section{ЛИТЕРАТУРА}

1. Макаров М.Л. Основы теории дискурса - М.: ИТДГК «Гнозис», 2003. -280 с.

2. Матвеева Г.Г. Основы прагмалингвистики. Монография - М.: Флинта, 2015. - 232 с.

3. Наер В.Л. Прагматика текста и ее составляющие // Сб. науч. тр. МгпиИЯ им М. Тореза. Вып. 245. 1985. - С. 35-37.

4. Столнейкер Р.С. Прагматика // Новое в зарубежной лингвистике: Вып. 16. Лингвистическая прагматика. - М.: Прогресс, 1985. - С. 419-432.

5. Телия В.Н. Русская фразеология. Семантический, прагматический и лингвокультурологический аспекты. - М.: Языки русской культуры, $1996 .-288$ с.

6. Yan Huang Pragmatics. Oxford University Press, USA. 2015. - 491 c.

7. Istvan Kecskes Intercultural Pragmatics. Oxford University Press. 2013. - 288 c.

8. Culpeper, Jonathan, Haugh, Michael. Pragmatics and the English language. Palgrave Macmillan. 2014. - 317 c.

9. Klaus P. Schneider, Anne Barron. Pragmatics of Discourse. De Gruyter Mouton. 2014. - 628 c.

10. Alessandro Capone, Marco Carapezza, Franco Lo Piparo. Further Advances in Pragmatics and Philosophy: Part 2 Theories and Applications. Springer International Publishing. 2019. $-590 \mathrm{c}$.

11. Gunter Senft. Understanding Pragmatics. Routledge. 2014. - 232 c.

12. Betty J. Birner. Introduction to Pragmatics. Wiley-Blackwell. 2012. - 340 c.

13. Paul R. Kroeger. Analyzing meaning: An introduction to semantics and pragmatics Language. Science Press. 2018. - 502 c.

14. Stephen C. Levinson. Pragmatics. Cambridge University Press. 1983. - 436 c.

15. Betty J. Birner. Introduction to Pragmatics. Wiley-Blackwell. 2012. - 340 c.

16. Bruce Fraser, Ken Turner. Language in Life, and a Life in Language: Jacob Mey - a Festschrift. Emerald Group. 2009. - 654 c.

17. Keith Allan, Kasia M. Jaszczolt. The Cambridge Handbook of Pragmatics. 2012. - 788 c.

18. Alessandro Capone, Jacob L. Mey. Interdisciplinary Studies in Pragmatics, Culture and Society. Springer International Publishing. 2016 - 980 C.

19. Marina Sbisa, Ken Turner Pragmatics of Speech Actions. de Gruyter Mouton. 2013. - 744 c.

20. Miriam A. Locher, Andreas H. Jucker. Pragmatics of Fiction. De Gruyter Mouton. 2017. - 629 c.

21. Арсентьева Е.Ф. Роль контекстуальных преобразований фразеологизмов в создании юмористического эффекта в литературном анекдоте // Ученые записки Казанского университета. Серия Гуманитарные науки. №3, 2006. - С.36-41.

22. Артемова А.Ф. Английская фразеология: спецкурс. Учебное пособие. М.: Высшая школа, 2009. - 208 с.

23. Баркова Л.А. Прагматические свойства фразеологизмов и их речевая реализация (на материале англоязычной журнальной рекламы) // (б. научных трудов МГПиИЯ им. М. Тореза. Вып. 198: Фразеология и контекст. 1982. - С. 3-13.

24. Божко Н.А. Индивидуально-авторские преобразования фразеологических единиц в языке художественной прозы (На материале произведений В.Токаревой). Автореф. ... дис. канд. филол. наук. - Тюмень, 2015. - 23 с.

25. Мелерович А.М., Мокиенко В.М. Окказиональные преобразования фразеологических единиц // Вестник Вестник Южно-Уральского государственного гуманитарно-педагогического университета. №8. 2014 - С. 234-252.

26. Третьякова И.Ю. Окказиональная фразеология: монография / И.Ю. Третьякова. - Кострома: КГУ им. Некрасова, 2011. - 290 с.

27. Третьякова И.Ю. Окказиональные преобразования фразеологизмов: интенсификация значения // Вестник КГУ. - 2018. - №4. - С. 166-169.

28. Федуленкова Т.Н., Воронин Р.А. Окказиональное преобразование фразеологических единиц как лингвистическое явление (о вкладе А.С. Начисчионе в разработку проблемы) // Вестник (ВФУ. - 2012. - №3. - С. 126-130.

29. Булаева Н.Е., Давыдова М.М. Окказиональные преобразования фразеологических единиц // Российский гуманитарный журнал. 2018. №6. С.482-489. DOI: 10.15643/libartrus-2018.6.5.

30. 30. Гимадеева А.А. Функционирование фразеологических единиц с компонентом-зоонимом в разговорном стиле речи (на материале татарского и английского языков) // Вестник ТГгПУ. 2010. - №21. - С.162-165.

31. Новикова О.В. Эффективные приемы структурно-семантического преобразования зоопословиц в англоязычной прозе // МНКО. 2020. - №1 (80). - С. 437-439. D0I:10.24411/1991-5497-2020-00175.

32. Киссел Ю.А. Окказиональное использование фразеологических единиц в произведениях Б.Шоу и 0. Уальда. Воронеж: Изд-во ВГУ, 1976. - 101 с.

33. Кунин А.В. Двойная актуализация как понятие фразеологической стилистики // Иностранные языки в школе. № 6. М., 1974. - С. 5-12.

34. Начисчионе А.С. Окказиональное стилистическое использование фразеологических единиц (на материале произведений Дж. Чосера): Автореф. дис. ... канд. филол. наук. М., 1976. - 21 с.

35. Халатникова Э.И. Эффект двойной актуализации во фразеологии и контекст (На материале современной английской и американской драматургии) 
// Фразеология и контекст: Межвуз. сборник научных трудов Куйбышевского пед. института-та. -Т. 265. 1982. - С. 70-78.

36. Болдырева Л.М. Стилистические особенности функционирования фразеологизмов: Автореф. дис. ... канд. филол. наук. - М., 1967. - 27 с.

37. Wodehouse P.G. Uncle Fred in Springtime. London: Penguin Books, 1979. - 223 p.

38. Macdonald R. The Drowning Pool. London: Michael Joseph Ltd, 1992. - 218 p.

39. Халатникова Э.И. Структурно-семантический и стилистический аспект цепочек сложных преобразований фразеологических единиц // Сб. науч. тр.

МГПИИЯ им. М. Тореза. - Вып. 198: Фразеология и контекст. 1982. - С. 215-226.

40. Wallace I. The Celestial Bed: Dell Book, 1988. - 369 p.

(с) Новикова Ольга Вячеславовна (Novikova_English@mail.ru).

Журнал «Современная наука: актуальные проблемы теории и практики»



